Е. Н. Гордиенко

ФГБОУ ВО Амурская ГМА

Минздрава России

г. Благовещенск

\section{К 70-ЛЕТИЮ ВЕЛИКОГО КИТАЯ - СОСЕДА РОССИИ. АГМА - ХГМУ: ИСТОРИЯ ВЗАИМОДЕЙСТВИЯ В ЕДИНСТВЕ ЦЕЛЕЙ}

В стратегии развития системы высшего медицинского образования важная роль отведена взгляду на традиции и особенности его организации для процветания современной медицины. В связи с этим мы вносим в обсуждение высказывание российского академика Д. С. Лихачева: «Прошлое - это стрела, направленная в будущее, и указывающая, каким ему быть». Есть потребность оценить факты прошлого, если они могут послужить будущему. Очень важной основой взаимоотношений двух великих стран - соседей является взаимный глубокий интерес друг к другу в разных сферах существования, в Т. ч. в образовании.

Наша Alma mater неумолимо приближается к своему 70-летию, равно как мир - к третьему десятилетию XXI века. 30 лет назад она так же, как и многие вузы мира, вступила в полосу интернационализации образования, включая обмен специалистами. Преподаватель, осмелившийся быть им в иностранном государстве, вне зависимости от своего опыта выступает в двух ипостасях. Его главная задача - достойно представлять, как гражданин России, своюAlma mater-Амурскую ГМА, и выполнить диктуемые договором цели и задачи, показав в новых условиях свою компетентность, профессионализм для того, чтобы быть востребованным иностранным учреждением - головным медицинским университетом провинции Хейлунцзян (ХГМУ).

Одновременно ему надо остаться собой, привыкнуть к новой обстановке восточной страны, заинтересованно принимающей его на территории своего кампуса. Поучительна и позитивна субъективная информация об особенностях периода адаптации иностранного специалиста к университету, профессорско-преподавательскому составу кафедры иностранных языков ХГМУ и студенческой аудитории, к укладу университетской жизни и, главное, к феномену начального этапа великого скачка Китая [1, $3,6,7]$, реализуемому успешно в начале 90-х годов, в том числе в сфере высшего медицинского образования. Приводим несколько аргументов.

1. Мир ХГМУ это территория высшего медицинского образования - университетский кампус, его особая атмосфера: несколько зеленых благоустроенных гектаров собственного университетского пространства на котором размещены административный корпус, учебные корпуса, здание библиотеки, научные центры и лаборатории, студенческие общежития, столовая, спортивный комплекс, жилые корпуса преподавателей и служащих ХГМУ, гостиница для иностранных преподавателей. Это действительно особый мир, целый город, уникальная среда для студенческой жизни: учеба, спорт, отдых, реже - развлечения, объединяют всех участников образования, как студентов и преподавателей, так и обслуживающий персонал. Попадая сюда, вчерашний школьник принимает как должное, регламент жизни, кодекс студента медика, включая правила проживания, учебы, работы, отдыха на несколько лет своего обучения в ХГМУ.

Резюме 1 октября 2019 года великий КНР торжественно отмечала 70-летний юбилей. Наша Родина - СССР - первой признала первое народное государство в Азии и 2.10 .1949 года установила с Китайской Народной Республикой дипломатические отношения. «Они строятся на принципах глубокого взаимного доверия в политической сфере, взаимного уважения, равенства, поддержки и учета коренных интересов друг друга, уважения суверенитета, территориальной целостности и выбора пути развития другой стороны, невмешательства во внутренние дела друг друга и деидеологизированности, строгого соблюдения норм международного права» (8). Обсуждается опыт работы Амурской ГМА в начале 90-х годов по обмену специалистами с Харбинским государственным медицинским университетом (ХГМУ) в системе высшего медицинского образования (ректор В.А. Доровских). Представлены впечатления российского преподавателя от знакомства с образовательной системой ХГМУ, направленной уже в начале 90-х годов на стабильное развитие в Китае приоритетов «школа - вуз - здравоохранение - развитое общество». Существование общих целей, задач, проблем в системе высшей школы России и большинства стран с высокой культурой обязывает совершенствовать высшее медицинское образование не только в системе европейских стандартов, но и с учетом опыта великого восточного соседа. Это реально только в условиях продолжающегося в XXI веке международного сотрудничества (ректор ФГБОУ ВО Амурская ГМА Минздрава России Т.В. Заболотских), информированности об опыте другого, знакомстве с образовательной системой иностранного партнера и его объектами.

Ключевые слова: ХГМУ - 30 лет назад, педагогика понимания и сотрудничества, единство целей высшего медицинского образования. 
2. Образование в ХГМУ начинается с библиотеки. Великолепный современный 4-х этажный корпус университетской "читальни», работающий ежедневно до 21.00. Гигантский по тем временам фонд как отечественной, так и иностранной литературы, включая в подлиннике периодические научные издания на английском языке по всем отраслям медицины, всю нашу, еще советскую, научную медицинскую периодику со свободным доступом. Предметом гордости за нашу страну явилось наличие наряду с научной литературой фонда художественно-публицистической и научнопопулярной литературы. Это были популярные в СССР, новой России толстые журналы «Новый мир», «Октябрь», «Знамя», «Иностранная литература», "Юность», образовательные педагогические серии «Знание-сила» и многие другие. Обрадовали портреты наших великих ученых, знание русского языка главным библиотекарем. Библиотека предоставляла равные возможности для работы как научным сотрудникам, так и начинающим студентам. В то время еще не было компьютерных классов, однако множительная техника экономила драгоценное учебное и личное время. Широко использовались ларингофонные классы с аудиотеками для изучения иностранных языков, включая самый престижный на долгое время - русский. Для озвучивания текстов и последующей работы с ними студентов привлекались русские преподаватели.

3. Современная научно-исследовательская база университета, в том числе лаборатория электронной микроскопии с 4-мя востребованными во всем мире японскими трансмис- сионными электронными микроскопами, на которых свои объекты изучал известный микробиолог профессор Ли Пу и другие ученые. Медицинский университет имел уже на тот период собственные базовые клиники, оснащенные современным диагностическим и лечебным оборудованием, где можно было самим убедиться в целительных чудесах восточной - традиционной китайской медицины и наличии современных европейских диагностических методов. Несомненен существующий в клинике приоритет методов восточной медицины: иглотерапия, мануальная терапия, фармакотерапия, цигун. Главным свидетельством их уникальности и востребованности во всем мире являются результаты лечения тяжелых больных с церебральной недостаточностью, которых приносили в стационар на руках, но выходили пациенты из клиники самостоятельно. Однако овладение джень-цзю требует многих лет, великого профессионализма и вдохновения как преподавателя, так и студента. Предоставленная для нас эта возможность явилась только «прикосновением».

4. Надежно функционировала отлаженная система организации учебы и жизни китайских студентов в варианте престижных образовательных центров Англии, Америки с коллективным принципом обучения, проведения досуга и отдыха в оптимальных условиях, созданных на территории кампуса. День для всех начинался с зарядки, адаптированной для разного возраста, на разных площадках под руководством тренера и с музыкальным сопровождением. Это означало действительно эффективный настрой на учебу

\title{
TO THE 70TH ANNIVERSARY OF GREAT CHINA - THE NEIGHBOR OF RUSSIA. ASMA - HSMU: A HISTORY OF INTERACTION IN A UNITY OF PURPOSES
}

\section{E. N. Gordienko}

\section{FSBEI HE the Amur State Medical Academy of the Ministry of Health of Russia, Blagoveshchensk}

\begin{abstract}
On October 1, 2019, great China will solemnly celebrate its 70th anniversary. Our Motherland - the USSR - was the first to recognize the FIRST People's State in Asia and on October 2, 1949 established diplomatic relations with the People's Republic of China. "They are built on the principles of deep mutual trust in the political sphere, mutual respect, equality, support and consideration of each other's fundamental interests, respect for sovereignty, territorial integrity and the choice of the other side's development, non-interference in each other's internal affairs and deideologization, strict adherence to standards of international law"(8) The experience of the Amur State Medical Academy in the early 90's on the exchange of specialists with Harbin State Medical University in the system of higher medical education (rector V. A. Dorovskikh) is discussed. The impressions of the Russian teacher from acquaintance with the educational system of HSMU, which was aimed at the very beginning of the 90s towards the stable development of the priorities "school - university - health care - developed society" in China are presented. The existence of common goals, objectives, problems in the system of higher education in Russia and most countries with a high culture obliges to improve higher medical education not only in the system of European standards, but also taking into account the experience of the great eastern neighbor. This is real only in the context of ongoing international cooperation in the 21st century (Rector of the Amur State Medical Academy T.V. Zabolotskikh), awareness of the experience of another, acquaintance with the educational system of a foreign partner and its facilities.
\end{abstract}

Key words: HSMU - 30 years ago, pedagogy of understanding and cooperation, unity of goals of higher medical education. 


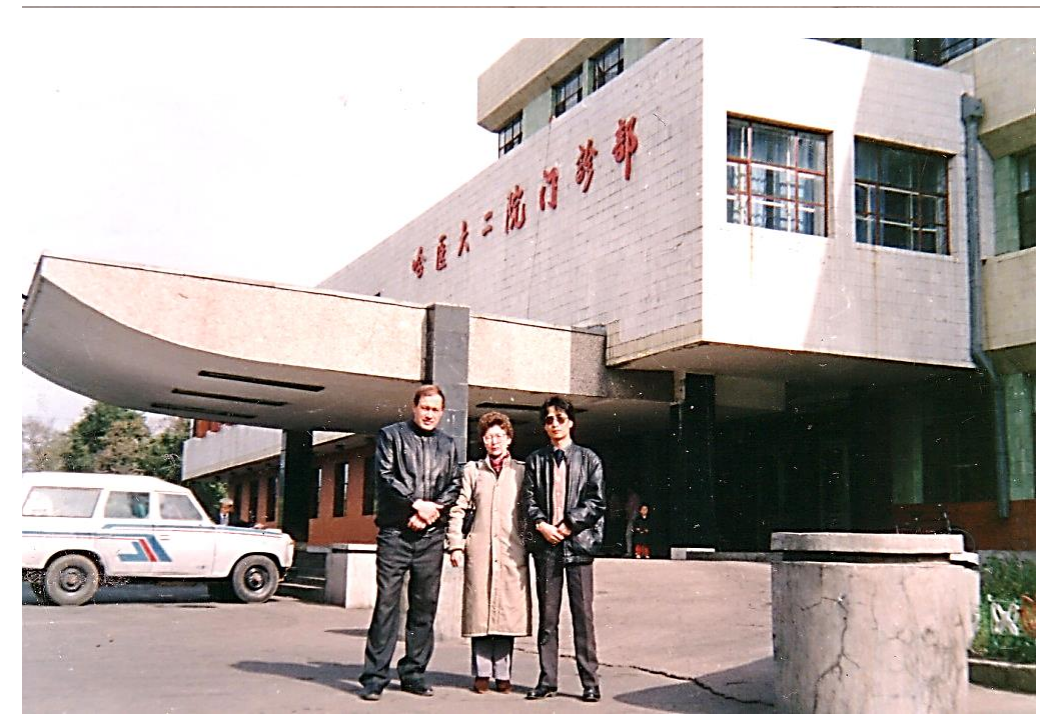

Клиника ХГМУ, оснащена современным оборудованием, востребована пациентами. Справа - Лю-Джень молодой талантливый специалист во всех отраслях традиционной восточной медицины.

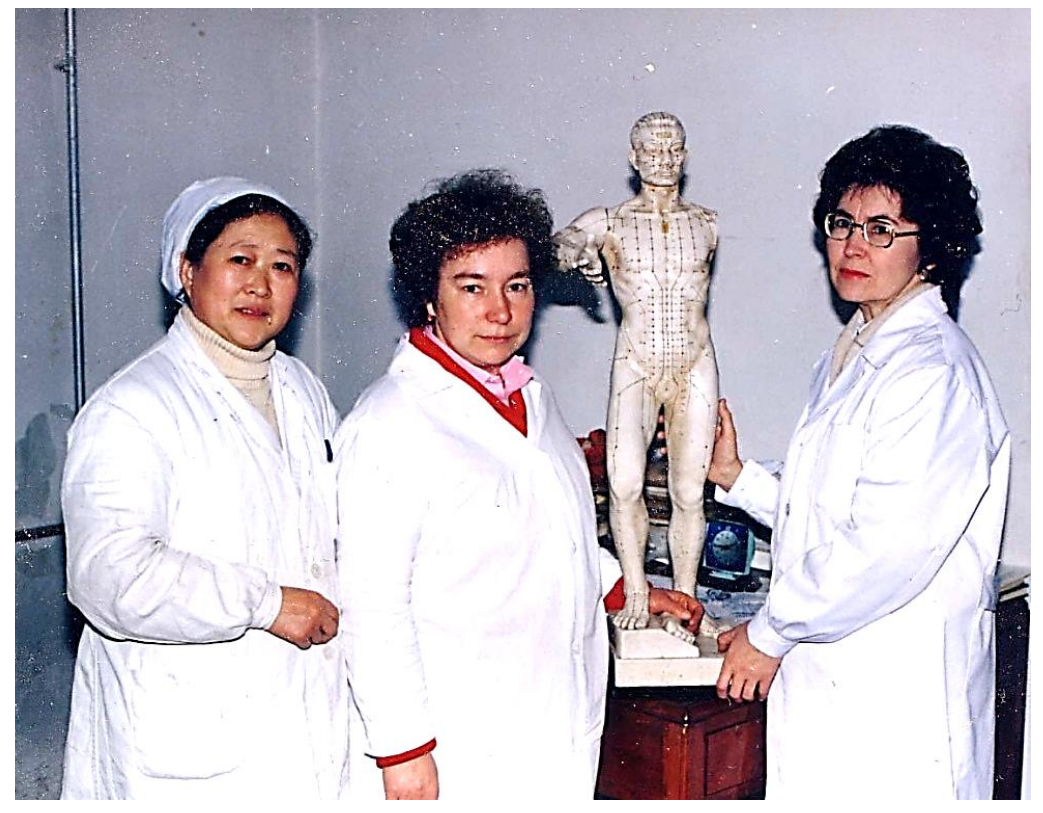

На занятиях по иглоукалыванию с профессионалом-профессором. С огромным терпением нам прививают навыки Джен-цзю-терапии. Фигуру китайского человека знает весь мир. Сегодня приверженцев восточной медицины в мире больше, чем 25 лет назад, и не случайно...

и здоровый образ жизни. Работала система социальной защиты студента - бесплатные питание, проживание в общежитии и другое. Перечень достоинств в организации высшего медицинского образования глазами иностранного преподавателя можно продолжить.

\section{Доминантным, на наш взгляд, оказался факт превращения (трансформации)} иностранного преподавателя из субъекта образования при осуществлении своих непосредственных функций в объект «исследования" - знакомства, пристального внимания как со стороны китайских преподавателей, так и студентов (рис. 5). Это обстоятельство не позволяет приехавшему специалисту работать «спустя рукава». Однако если ему сопутствует проявление доверия со стороны студентов и преподавателей, это делает его пребывание оправданным, востребованным, успешным и творческим. Нам в этом повезло: впечатления от преподавания и взаимного общения оказались незабываемыми!
Важно было увидеть самим и убедиться в таланте китайских преподавателей не только учить предмету, остаться требовательными, но и быть сопричастными, заинтересованными в успехах и проблемах своих студентов. Мы получили реальную возможность увидеть педагогику наставничества - понимания и сотрудничества в действии (рис. 6). Не только декларация обязанностей и ответственности, но и признание прав молодого человека, в том числе на участие в сложном процессе его адаптации к новым условиям жизни и учебы, новому коллективу сверстников, к "вхождению в медицину», к дальнейшему повышению квалификации. Профессионализм преподавателя зависит от его личной заинтересованности и возможности сделать процесс преподавания не только научным, перспективным, доступным, побуждающим к творчеству, но и наставляющим (воспитывающим), формирующим в процессе обучения личность врача - целителя, это то, что называют «воспитание через образование».

Два пути: роль «ведущего» для учителя и «ведомого» для студента или "совместное 


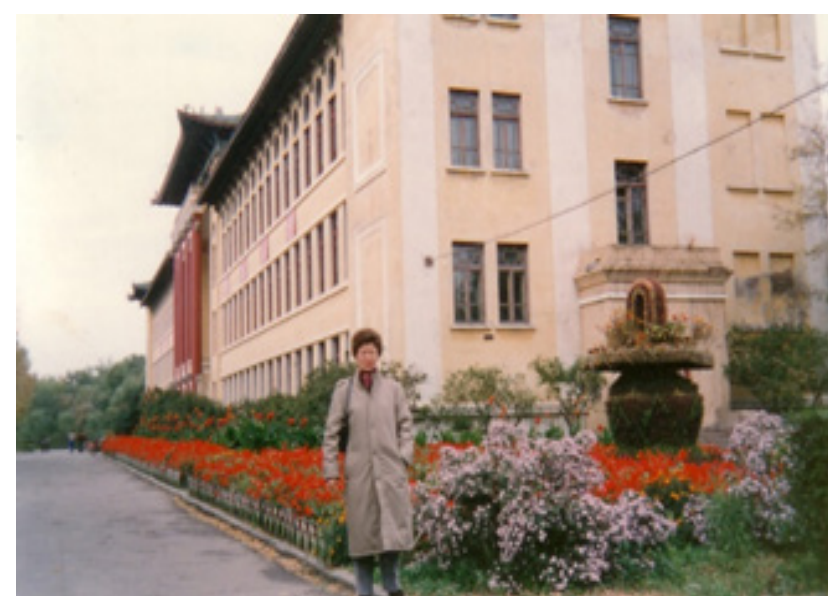

Административный корпус ХГМУ. До декабря утопает в цветах. Здесь же - кафедра иностранных языков, студенческие аудитории.

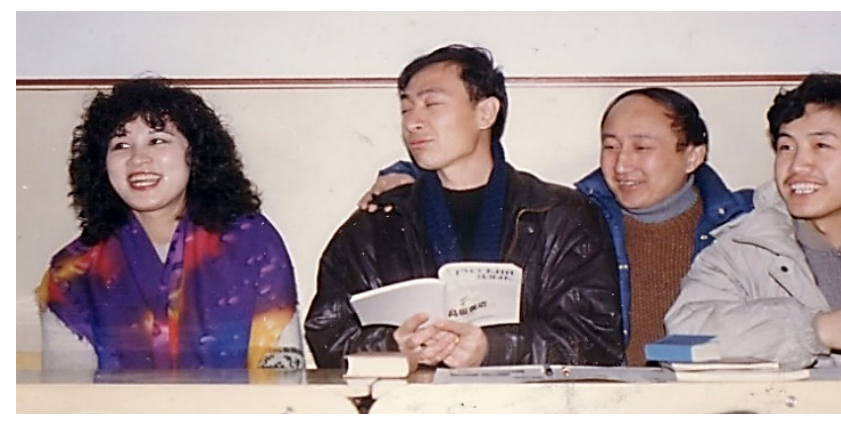

Курсанты-врачи на уроках русского языка: составляем тексты на трудном русском, но делаем это весело, несмотря на прохладную аудиторию, потому что вспоминаем интересные случаи из своей жизни (1992 г.).

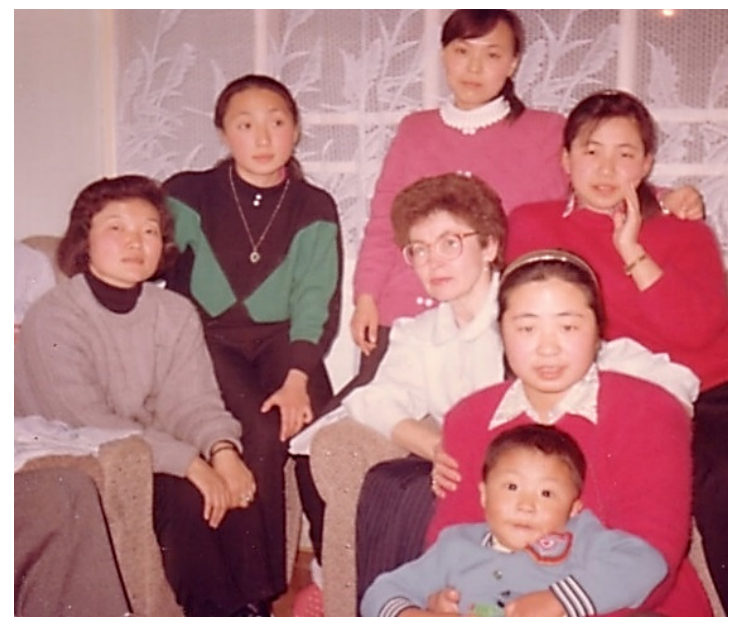

В гостях у семьи профессора Ли (кафедра иностранных языков), знатока русского языка, прекрасного педагога: его студенты, преподаватель из России, маленький любимый внук Ляо-Ляо. Всем тепло, уютно и есть, что обсудить. движение по лабиринтам образования» были талантливо совмещены великолепным филологом профессором Ли и рождали доверие и признание со стороны «ведомых» и веру в них со стороны «ведущего». Именно это единение объекта и субъекта образования рождает позитивный результат «целеустремленность - усердие - успех в достижении цели - ЗНАНИЕ, проникнутое уважением к учителю»! Конфуций выразил это короткой фразой «Мир должен быть одушевлен разумом».

Наш опыт свидетельствует, что главные принципы, их личностные проявления у китайских и российских студентов - будущих врачей, едины. Они уверены в престижности своей профессии и будучи целесообразными, выбирают профессионализм, целеустремленность, усердие и креативность. Обучаясь догмам единого врачебного долга, они являются патриотами своей страны, но стремятся познавать другой мир, мир своих сверстников. В стенах университета и академии студенты воспитываются в традициях уважения к выбранной профессии, к труду врача и преподавателя, готовятся к исполнению врачебного долга.

\section{Выводы}

Обосновывается справедливость фразы "XXI век - век образования», соответствующей современной концепции всей системы высшей школы, включая и медицинскую - в Китае, в России как цивилизованных странах мира. Решается главная задача подготовка профессиональных врачебных кадров для страны, в России - для гигантского по своим масштабам Дальневосточного региона, включая Амурскую область. Многие идеи, цели и задачи, реализуемые высшим медицинским образованием, являются едиными для государств, ставящих своей главной целью «перспективное развитие здоровое население - здоровое общество».

Знакомство, изучение, совместный анализ изаинтересованноеобсуждение общих задач и проблем медицинского образования и воспитания позволяют избирать правильную стратегию развития в системе предиктивной медицины во благо здоровья как населения наших стран, так и мировой цивилизации XXI века. Современная медицинская школа в своих целях глобально и личностно значима, так как она объединяет интересы начинающих студентов, преподавателей, врачей профессионалов, политиков, государств, народов. Этот сложный и перспективный процесс предполагает дальнейшую интеграцию деятельности, ее продолжение на пути международного сотрудничества.

\section{Литература}

1. Гумилев Л. Н. Три китайских царства. М.: Алгоритм, Эксмо, 2008. 272 с. 


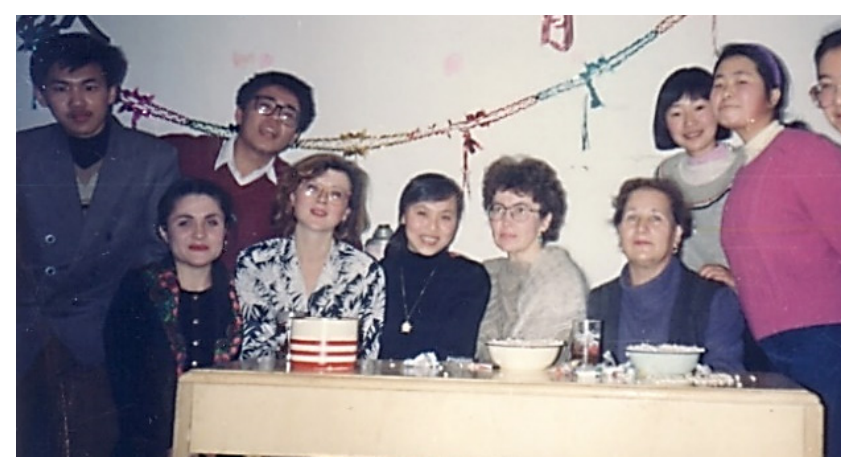

Замечательные вечера со студентами, когда можно поговорить обо всем, попеть песни («Подмосковные вечера», ...), нарисовать шаржи друг на друга, посмеяться. Приглашены и студенты Амурской ГМА, обучающиеся в Университете традиционной восточной медицины (1992).

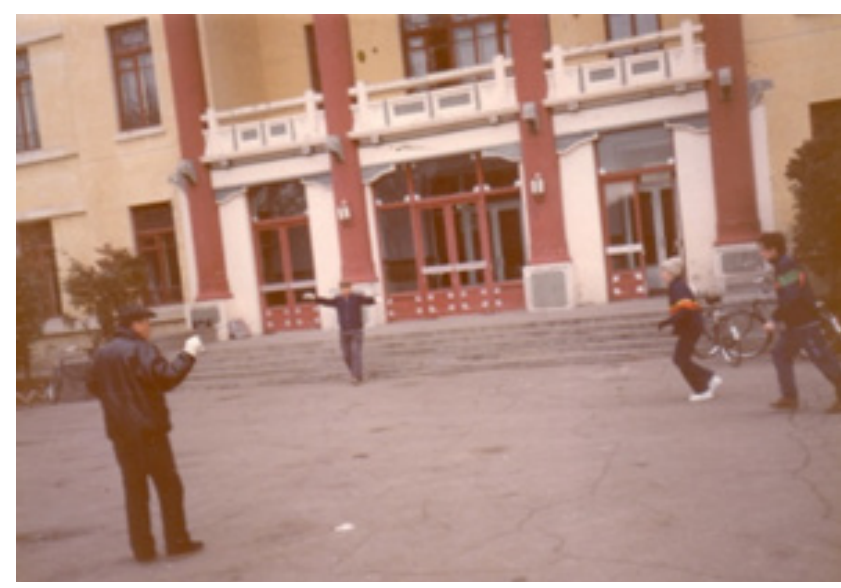

Каждое раннее утро для всех начинается с зарядки. Каждая возрастная группа имеет свою территорию, где звучит музыка, и сон уходит прочь.

2. Дерюга В. Е. Базовые категории педагогики: человек, воспитание, образование, культура // Проблемы современного образования, 2010. №5. С. 19-29

3. Елисеев Д. Корни настоящего. СПб.: Евразия, 2008. 311 с.

4. Конфуций. Беседы и суждения: Трактат / Пер. с кит. М.: Мир книги. Литература, 2009. $352 \mathrm{c}$.

5. Цэнь Юйфэн. Лучшее в китайском цигун. СПб.: «Северо-Запад», 2009. 348 с.

6. Фишмен Т. Китай INC. Восход сверхмощного глобального конкурента. М.: Эксмо, 2007. 444 c.

7. Shambaugh D. China and Europe: The Emerging Axis, Current History. September 2004. C. 243-249.

8. http://orkd.ifesras.ru/index.php?mac$\mathrm{t}=$ News, cntnt01, detail, $0 \&$ cntnt01articleid $=341 \&$ cntnt 01 origid $=60 \&$ cntnt 01 re turnid $=60$
9. https://dknews.kz/selkovyi-put/70-letie-ustanovlenia-dipotnosenii-mezdu-kitaem-i-rossiei. html

\section{Статья поступила в редакцию 13.09.2019}

\section{Координаты для связи}

Гордиенко Елена Николаевна, д.М.н., профессор кафедры гистологии и биологии ФГБОУ ВО Амурская ГМА Минздрава России.

Почтовый адрес ФГБОУ ВО Амурская ГМА Минздрава России: 675000, Амурская область, г. Благовещенск, ул. Горького, 95. E-mail: AmurSMA@AmurSMA.su, science.dep@ AmurSMA.su 